\title{
Assessing asthma control: questionnaires and exhaled nitric oxide provide complementary information
}

\section{To the Editor:}

Current asthma guidelines propose the use of quantitative composite measures of asthma control for assessment and follow-up [1]. The use of inflammatory markers within the definition of control in asthma guidelines has been recently suggested [2]. Sputum eosinophilia has been proposed as a useful surrogate marker of airway inflammation [3] but it is time-consuming and unfeasible in many clinical settings. In contrast, exhaled nitric oxide fraction $(F \mathrm{eNO})$ is easily measured, well correlated with eosinophilic airway inflammation [4] and has been used in routine asthma care [5]. However, to be included in the assessment of asthma control it should provide additional information. Factor analysis is a statistical method used to uncover which sets of variables form coherent subsets that are relatively independent of one another, and to obtain a small number of factors that account for most of the variance. We therefore aimed to assess the contribution of FeNO in the variability of asthma control using factor analysis.

We performed a cross-sectional study of 174 consecutive asthma patients ( $82 \%$ female, $70 \%$ atopic, $76 \%$ nonsmokers and $72 \%$ using inhaled steroids), with a mean \pm SD age of $40 \pm 15$ yrs (table 1). Patients were assessed using FeNO (NIOX ${ }_{\mathbb{R}}$; Aerocrine, Solna, Sweden) measurements [6], forced expiratory volume in one second (FEV1; PIKO-1®; Ferraris, Hertford, UK) and the Asthma Control Questionnaire (ACQ) [7]. A factor analysis using principal components as the method of extraction was conducted to explore the correlation between the following eight outcome measures: shortness of breath, morning symptoms, night-time symptoms, activity limitations, wheezing, use of bronchodilators, FEV1 \% predicted and FeNO. Relationships between FeNO, FEV1 and ACQ were investigated using Pearson's correlation coefficients with a level of statistical significance set of $p \leqslant 0.05$. The study was approved by the Local Ethics Committee (Porto, Portugal) and informed consent was obtained.

\begin{tabular}{ll} 
TABLE 1 & $\begin{array}{l}\text { Clinical characteristics of } 174 \text { consecutive } \\
\text { asthma patients evaluated using the Asthma } \\
\text { Control Questionnaire (ACQ) and exhaled nitric } \\
\text { oxide fraction (FenO) }\end{array}$ \\
Age yrs & $40 \pm 15$ \\
Female & $142(82)$ \\
Atopy & $121(70)$ \\
Rhinitis & $116(67)$ \\
ACQ score & $1.22(1.07-1.37)$ \\
FEV $\%$ pred & $87.5(24.7)$ \\
FeNo ppb & $29.3^{\#}(26.1-32.8)$ \\
\hline
\end{tabular}

Data are presented as mean $\pm \mathrm{SD}, \mathrm{n}(\%)$ or mean (95\% confidence interval). FEV1: forced expiratory volume in one second; \% pred: \% predicted. \#: geometric mean.
The mean ACQ score was 1.22 (range $0.0-4.7$ ), and 52\% patients had well-controlled asthma (ACQ score <1.0).

Factor analysis yielded three factors that explained $77 \%$ of the variance: ACQ score (50\%), FEV1\% pred (14\%) and FeNO (13\%; table 2). No significant correlation between FeNO and ACQ score was observed, while FeNO and FEV1 had a weak but significant correlation $(r=0.243, p=0.001)$.

Our data support the hypothesis that airway inflammation, clinical questions and lung function, addressed by FeNO and $A C Q$, are complementary for the evaluation of asthma status in adult patients. However, the cross-sectional nature of our study limits the interpretation of results, since exacerbations and other temporal variations could not be addressed. Nevertheless, this is the first study to quantitatively assess the contribution of $\mathrm{FeNO}$ and an asthma control measurement instrument for the variance of asthma status.

Although a few asthma studies have previously included inflammatory markers [8-10], none simultaneously reported factor analysis results on clinical variables, lung function and airway inflammation. Rosi et al. [8] identified three components in clinically stable asthmatics: airway function, airway responsiveness, and eosinophilic inflammation assessed using sputum analysis. In steroid-naïve asthma patients, the relationship between these parameters seems to be dependent on the duration of the disease [9]. In the only study in which asthma symptoms were evaluated, weak correlations were observed in

\begin{tabular}{lccc} 
TABLE 2 & $\begin{array}{l}\text { Factor analysis of asthma variables in all } \\
\text { patients: factor loading } \\
\text { matrix }\end{array}$ \\
\cline { 2 - 4 } & \multicolumn{3}{c}{ Factor } \\
\cline { 2 - 4 } & $\mathbf{1}$ & $\mathbf{2}$ & $\mathbf{3}$ \\
\hline & $0.873^{\#}$ & -0.046 & -0.099 \\
Shortness of breath & $0.871^{\#}$ & 0.108 & -0.060 \\
Morning symptoms & $0.824^{\#}$ & 0.052 & 0.083 \\
Night-time symptoms & $0.817^{\#}$ & -0.144 & -0.095 \\
Activity limitations & $0.790^{\#}$ & -0.241 & 0.112 \\
Wheezing & $0.715^{\#}$ & -0.181 & 0.181 \\
Use of bronchodilators & -0.087 & $0.976^{\#}$ & 0.047 \\
FEV 1 & 0.016 & 0.044 & $0.981^{\#}$ \\
FeNo ppb & 50 & 14 & 13 \\
Variance explained by the factors \%" & & & \\
\hline
\end{tabular}

Extraction method used: principal components analysis; rotation method used: varimax. Factor 1 contains six questions from the Asthma Control Questionnaire; factor 2 contains forced expiratory volume in one second ( $\left.F E V_{1}\right)$, factor 3 contains exhaled nitric oxide fraction $\left(F_{e N O}\right)$. ppb: parts per billion. \#: highest factor loading of a variable; " accumulated percentage variance is $77 \%$ 
children between composite score of asthma severity, atopic parameters and FeNO [10].

In conclusion, clinical questions of the Asthma Control Questionnaire, forced expiratory volume in one second and exhaled nitric oxide fraction were grouped in distinct components, suggesting that they may complement each other in the assessment of asthma status. Further research, particularly observational longitudinal studies, should assess the usefulness of inflammatory biomarkers in conjunction with clinical questions and lung function parameters in asthma control assessment, and eventually establish an algorithm for treatment adjustment based on a thorough measure of asthma control.

\section{Lopes ${ }^{* \#}$, J. Fonseca ${ }^{*}$, , L. Delgado*,\#, A. Moreira ${ }^{*, \#,}$ R. Barros $^{+}$, P. Moreira ${ }^{+, \S}$, M. da G. Castelo-Branco*}

*Immuno-allergology Division, Hospital of São João, "Dept of Immunology, Faculty of Medicine, "Biostatistics and Medical Informatics Division and Center for Research in Health Information Systems and Technologies (CINTESIS), Faculty of Medicine, ${ }^{+}$Faculty of Nutrition and Food Sciences, and ${ }^{\S}$ Research Centre in Physical Activity, Health and Leisure, University of Porto, Porto, Portugal.

\section{STATEMENT OF INTEREST}

None declared.

\section{ACKNOWLEDGEMENTS}

The present authors would like to thank J. Ferraz de Oliveira (Immuno-allergology, Hospital of São João, Porto, Portugal) for help in study planning.

\section{REFERENCES}

1 National Institutes of Health, National Heart Lung, and Blood Institute, Global Strategy for Asthma Management and Prevention - Global Initiative for Asthma (GINA). www.ginasthma.org Date last updated: 2007. Date last accessed: December 2007.

2 Smith AD, Cowan JO, Brassett KP, Herbison GP, Taylor DR. Use of exhaled nitric oxide measurements to guide treatment in chronic asthma. N Engl J Med 2005; 352: 2163-2173.

3 LeBlanc A, Robichaud P, Lacasse Y, Boulet LP. Quantification of asthma control: validation of the Asthma Control Scoring System. Allergy 2007; 62: 120-125.

4 Jatakanon A, Lim S, Kharitonov SA, Chung KF, Barnes PJ. Correlation between exhaled nitric oxide, sputum eosinophils, and methacholine responsiveness in patients with mild asthma. Thorax 1998; 53: 91-95.

5 Michils A, Baldassarre S, Van Muylem A. Exhaled nitric oxide and asthma control: a longitudinal study in unselected patients. Eur Respir J 2008; 31: 539-546.

6 Recommendations for standardized procedures for the online and off-line measurement of exhaled lower respiratory nitric oxide and nasal nitric oxide in adults and children -, This official statement of the American Thoracic Society was adopted by the ATS Board of Directors, July 1999. Am J Respir Crit Care Med 1999 1999; 160: 2104-2117.

7 Juniper EF, Bousquet J, Abetz L, Bateman ED. Identifying "well-controlled" and "not well-controlled" asthma using the Asthma Control Questionnaire. Respir Med 2006; 100: 616-621.

8 Rosi E, Ronchi MC, Grazzini M, Duranti R, Scano G. Sputum analysis, bronchial hyperresponsiveness, and airway function in asthma: results of a factor analysis. J Allergy Clin Immunol 1999; 103: 232-237.

9 Gronke L, Kanniess F, Holz O, Jorres RA, Magnussen H. The relationship between airway hyper-responsiveness, markers of inflammation and lung function depends on the duration of the asthmatic disease. Clin Exp Allergy 2002; 32: 57-63.

10 Leung TF, Wong GW, Ko FW, Lam CW, Fok TF. Clinical and atopic parameters and airway inflammatory markers in childhood asthma: a factor analysis. Thorax 2005; 60: 822-826.

DOI: 10.1183/09031936.00093008

\section{Breathless after separation... from tumour}

\section{To the Editors:}

It is a general property of the G-protein coupled receptor family, which includes adrenergic receptors, to attenuate their response after persistent stimulation [1]. However, the airway tolerance to $\beta_{2}$-agonists and the phenomenon of rebound bronhoconstriction after $\beta_{2}$-agonist withdrawal seems not to have clinical significance [2] even though it differs between compounds [3].

Herein, we report the case of a patient who developed severe bronchial obstructive symptoms after sudden interruption of a chronic stimulation of the airway catecholamine receptors by their endogenous agonists.

The patient was an 84-yr-old, nonsmoking, healthy female with no previous history of asthma or lung disorders. She attended a gym regularly, where she observed that her resting cardiac frequency increased to 110 beats $\cdot \mathrm{min}^{-1}$. During the investigation of her tachycardia, a right-sided $48 \times 52 \times 55-\mathrm{mm}$ adrenal tumour was found. Laboratory testing of the patient's urine revealed highly increased levels of noradrenaline $\left(8,780 \mathrm{nmol} \cdot \mathrm{day}^{-1}\right.$; normal value $\left.<400 \mathrm{nmol} \cdot \mathrm{day}^{-1}\right)$ and $\mathrm{mod}-$

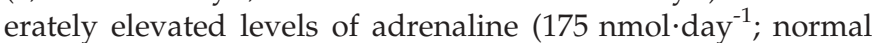
value $<80 \mathrm{nmol} \cdot \mathrm{day}^{-1}$ ) confirming the diagnosis of pheochromocytoma. The patient was prepared carefully for surgery by stepwise increase of the $\alpha$-blocker doxazosin to a dose of $32 \mathrm{mg}$ daily at the time of surgery and diltiazem (180 mg daily), which was preferred to $\beta$-blockers for treating her tachyarrhythmia. After successful laparoscopic removal of the tumour, the patient developed severe bronchospasm and had to be treated with glucocorticoids and inhaled $\beta_{2}$-agonists. The obstructive symptoms lasted $<1$ week. 